\title{
25-hydroxyvitamin D deficiency, exacerbation frequency and human rhinovirus exacerbations in chronic obstructive pulmonary disease
}

\author{
Jennifer K Quint ${ }^{1 *}$, Gavin C Donaldson ${ }^{1}$, Nancy Wassef ${ }^{2}$, John R Hurst ${ }^{1}$, Michael Thomas ${ }^{2}$ and Jadwiga A Wedzicha ${ }^{1}$
}

\begin{abstract}
Background: 25-hydroxyvitamin D deficiency is associated with COPD and increased susceptibility to infection in the general population.

Methods: We investigated whether COPD patients deficient in 25-hydroxyvitamin D were more likely to be frequent exacerbators, had reduced outdoor activity and were more susceptible to human rhinovirus (HRV) exacerbations than those with insufficient and normal levels. We also investigated whether the frequency of Fokl, Bsml and Taqla 25-hydroxyvitamin D receptor (VDR) polymorphisms differed between frequent and infrequent exacerbators.

Results: There was no difference in 25-hydroxyvitamin $D$ levels between frequent and infrequent exacerbators in the summer; medians $44.1 \mathrm{nmol} / \mathrm{L}(29.1$ - 68.0) and $39.4 \mathrm{nmol} / \mathrm{L}(22.3-59.2)$ or winter; medians $24.9 \mathrm{nmol} / \mathrm{L}(14.3$ 43.1) and $27.1 \mathrm{nmol} / \mathrm{L}(19.9-37.6)$. Patients who spent less time outdoors in the 14 days prior to sampling had lower 25-hydroxyvitamin D levels $(p=0.02$ ). Day length was independently associated with 25 -hydroxyvitamin $D$ levels $(p=0.02)$. There was no difference in 25 -hydroxyvitamin $D$ levels between baseline and exacerbation; medians 36.2nmol/L (IQR 22.4-59.4) and 33.3nmol/L (23.0-49.7); $P=0.43$. HRV positive exacerbations were not associated with lower 25-hydroxyvitamin $\mathrm{D}$ levels at exacerbation than exacerbations that did not test positive for HRV; medians 30.0nmol/L (20.4 - 57.8) and 30.6nmol/L (19.4 - 48.7). There was no relationship between exacerbation frequency and any VDR polymorphisms (all $p>0.05$ ).

Conclusions: Low 25-hydroxyvitamin D levels in COPD are not associated with frequent exacerbations and do not increase susceptibility to HRV exacerbations. Independent of day length, patients who spend less time outdoors have lower 25-hydroxyvitamin D concentration.
\end{abstract}

\section{Background}

Serum concentrations of 25-hydroxyvitamin D vary with age, race, sex, season and geographic location [1]. In its physiologically active form 25-hydroxyvitamin $\mathrm{D}$ is released into the circulation, binds to a carrier protein in the plasma (25-hydroxyvitamin D binding protein (DBP)) and is transported to various target organs where it mediates its biological effects by binding to the 25hydroxyvitamin D receptor (VDR) [2]. Deficiency in 25hydroxyvitamin $\mathrm{D}$ results from a number of causes and is associated with increased risk of infections including

\footnotetext{
* Correspondence: Jennifer.quint@lshtm.ac.uk

${ }^{1}$ Academic Unit of Respiratory Medicine, University College London Medical School, Royal Free Campus, Rowland Hill Street, London, UK

Full list of author information is available at the end of the article
}

influenza, TB and pneumonia [3]. VDR dysfunction, linked to 25-hydroxyvitamin D deficiency, is thought to cause a decline in innate immune function that increases susceptibility to infections [4].

COPD is characterised by irreversible expiratory airflow limitation [5]. The disease is interspersed with periods of exacerbation that have important consequences for patients and health care providers [6-10]. Exacerbations are predominantly triggered by infection and the commonest respiratory virus detected in the airways at exacerbation is human rhinovirus (HRV) $[11,12]$. Some individuals are more susceptible to developing exacerbations and these individuals are termed "frequent exacerbators" [13]. Frequent exacerbators have worse quality of life [6], greater limitation of their daily activity, spend

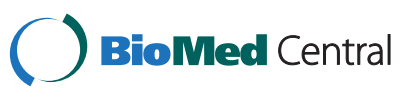

(c) 2012 Quint et al.; licensee BioMed Central Ltd. This is an Open Access article distributed under the terms of the Creative Commons Attribution License (http://creativecommons.org/licenses/by/2.0), which permits unrestricted use, distribution, and reproduction in any medium, provided the original work is properly cited. 
less time outdoors [14], have faster disease progression $[8,15,16]$ and greater airway inflammation [17] and increased mortality [18] compared to patients with infrequent exacerbations.

Exacerbations are approximately 50\% more likely in the winter [19]. It has been postulated that humans have improved innate immunity in the summer, impaired in the winter and that with 25-hydroxyvitamin D synthesis being so dependent on sunlight exposure, falling winter levels may trigger immune deficiencies [20]. It has also been shown recently that vitamin D deficiency is associated with increased mortality in patients admitted to hospital with community acquired pneumonia [21] and it is possible that vitamin D deficiency in COPD may increase susceptibility to pneumonia at the time of exacerbation. Genetic variants in the 25-hydroxyvitamin D pathway have been associated with chronic obstructive pulmonary disease (COPD) [22-26] and many polymorphisms in the VDR gene [27] have been linked with infection.

Our London COPD cohort, a well characterised group of patients allows us to study various aspects of 25hydroxyvitamin D deficiency on COPD. We hypothesised that with exacerbations peaking in the winter/early spring when 25-hydroxyvitamin D levels are at their lowest, this deficiency in 25-hydroxyvitamin D may increase exacerbation risk via changes in airway inflammation. As our primary outcome we investigated whether COPD patients deficient in 25-hydroxyvitamin D were more likely to be frequent exacerbators. We also investigated whether they had reduced outdoor activity, and were more susceptible to HRV at exacerbation than those with insufficient or normal levels. We investigated whether 25-hydroxyvitamin D levels correlated with HRV load. We also investigated whether the frequency of VDR polymorphisms differed between frequent and infrequent exacerbators.

\section{Methods}

\section{Patient recruitment}

Ninety seven COPD patients were studied between $1^{\text {st }}$ April 2006 and $30^{\text {th }}$ March 2009. The recruitment and monitoring of patients in the London COPD cohort has previously been described $[6,8,11,12,14,17]$. This study was approved by the Royal Free Hospital Research Ethics Committee (Ref: 05/Q0501/126) and patients gave written informed consent.

All patients had COPD as defined by a forced expiratory volume in one second $\left(\mathrm{FEV}_{1}\right)$ of $\leq 80 \%$ and $\mathrm{FEV}_{1}$ to forced vital capacity (FVC) ratio below $70 \%$ with $\beta_{2}$ agonist reversibility of less than $15 \%$ or $200 \mathrm{ml}$. Patients were excluded if they had other significant respiratory diseases. Patients were recruited when stable, with no exacerbations reported in the preceding month.
At the initial visit, daily respiratory symptoms, smoking history, drug history and co-morbidities were recorded. Height and weight were measured along with baseline lung function using a volumetric storage spirometer (Vitalograph 2160, Maids Moreton, Buckingham, UK). Blood was collected for 25hydroxyvitamin D assay. Summer samples were taken in June, July or August, and winter samples in January, February or March. Both samples were collected in each individual in the same 12 month period. In each patient, spontaneously produced sputum when available and a nasopharyngeal swab (NPS) were collected for HRV detection.

\section{Exacerbations}

COPD patients completed daily diary cards, recording any increase in daily respiratory symptoms. They were asked to contact the study team if they experienced an increase in their symptoms and were usually reviewed within 24 hours. Major symptoms were increased dyspnoea, sputum volume or sputum purulence and minor symptoms increased cough, wheeze, sore throat or coryzal symptoms. Exacerbations were defined according to our previously validated criteria of two symptoms (at least one major) for two consecutive days, or if in the opinion of the attending clinician, the patient had an exacerbation [17]. Our exacerbation definition has been validated against changes in quality of life [6], inflammatory markers [17], and $\mathrm{FEV}_{1}$ decline [8]. All exacerbations in this study were treated with antibiotics and steroids. None of the exacerbations required hospitalisation.

At an exacerbation visit information was collected on symptom type. The end of the exacerbation was taken as the last day on which lower airway symptoms were recorded. Spirometry was performed and blood taken for 25-hydroxyvitamin D assay. Sputum was collected if spontaneously produced and a NPS taken. All exacerbations were treated with bronchodilators, antibiotics and/or oral steroids as judged by the clinician. All samples were taken prior to the initiation of treatment. Exacerbation visits were not limited to summer or winter months and results were adjusted for seasonality.

\section{Exacerbation frequency}

Exacerbation frequency was determined from diary cards. Patients were defined as 'frequent exacerbators' if they had three or more exacerbations per year, or 'infrequent exacerbators' if they had less than three exacerbations per year $[28,29]$. 3 exacerbations were chosen as both treated and untreated exacerbations were included in our definition. 


\section{Time outdoors and daylength}

At the end of each day, patients record on diary cards the number of hours they have spent out of the house that day. The time outdoors for baseline and exacerbation visits was calculated as the average time spent outdoors in the 14 days preceding the clinic visit. Daylength data were obtained from Meteorological Office data (at Heathrow Airport, London) on the day of the visit to clinic.

\section{Patient blood sampling}

Seven millilitres of venous blood collected at baseline and exacerbation visits was centrifuged at $224 \mathrm{x} \mathrm{g}$ for 10 minutes at $4^{\circ} \mathrm{C}$ within two hours of collection. The serum was then separated and stored at $-80^{\circ} \mathrm{C}$ for later analysis.

\section{5-hydroxyvitamin D measurement}

Samples were assayed using the LIAISON 25-OH 25hydroxyvitamin D TOTAL (DiaSorin, Italy). The LIAISON 25-OH 25-hydroxyvitamin D TOTAL is a fully automated antibody-based two-step direct competitive chemiluminescence immunoassay (CLIA) in the clinical biochemistry department at the Royal Free Hospital. The assay recognises $100 \%$ 25-OH 25-hydroxyvitamin D2 and 25-OH 25-hydroxyvitamin D3 using magnetic micropeptide separation. The limit of detection is $\leq 4.0$ $\mathrm{ng} / \mathrm{ml}$. 25-hydroxyvitamin D deficiency was defined as $<25 \mathrm{nmol} / \mathrm{L}$, insufficiency $25-75 \mathrm{nmol} / \mathrm{L}$ and sufficiency $>75 \mathrm{nmol} / \mathrm{L}$ (conversion factor of 2.5 for $\mathrm{nmol} / \mathrm{L}$ from $\mathrm{ng} / \mathrm{ml}$ ). We chose to measure 25 -hydroxyvitamin $\mathrm{D}$ as there is a standardised assay for measurement which is widely used and previously published on. The serum concentration of 25-hydroxyvitamin D is typically used to determine vitamin $\mathrm{D}$ status as it reflects vitamin $\mathrm{D}$ produced in the skin as well as that acquired from the diet, and has a fairly long circulating half-life.

\section{Virus detection in NPS and sputum}

Samples were collected and processed according to our previously published methodology [28]. Briefly, patients were instructed to blow their nose prior to the swab being passed gently through the nose towards the posterior nasopharynx. The swab was rotated 5-6 times and allowed to remain in place for 5 seconds. The swab was then immediately placed in an eppendorf containing $0.5 \mathrm{ml}$ PBS (phosphate buffered saline) and stored at $-80^{\circ} \mathrm{C}$ until RNA extraction. Sputum samples were examined as soon as possible and within two hours of collection. The sample was separated from contaminating saliva and processed using previously published methods [30].

RNA was extracted from NPS using the High Pure Viral RNA kit (Roche) according to manufacturer instructions. RNA was extracted from sputum using Trireagent LS (Sigma) according to the manufacturer instructions. cDNA was prepared using the HighCapacity cDNA Reverse Transcription Kit (Applied Biosystems) following the manufacturer instructions. Realtime PCR was performed using the ABI Prism 7500 Real Time PCR System (Applied Biosystems). 25 $\mu$ l reaction volumes were set up $(12.5 \mu \mathrm{l}$ QuantiTect Probe PCR Master Mix (ROX reference dye, Qiagen), $1 \mu$ l forward and reverse primers $(20 \mu \mathrm{M}), 0.35 \mu \mathrm{l}$ probe $(20 \mu \mathrm{M}), 2.5 \mu \mathrm{l}$ template and $7.65 \mu \mathrm{l}$ RNase free water. PCR conditions: $95^{\circ} \mathrm{C} 15 \mathrm{~min}, 40$ cycles of $95^{\circ} \mathrm{C} 15 \mathrm{sec}$ and $58^{\circ} \mathrm{C} 80 \mathrm{sec}$. This methodology has been published previously [28].

\section{Genotyping}

Venous blood samples $(10-20 \mathrm{ml})$ were taken in EDTA tubes at the initial visit for all patients and control subjects and stored at $-80^{\circ} \mathrm{C}$ prior to DNA extraction. DNA extraction was performed using a Gentra ${ }^{\circledR}$ systems Puregene $^{\circledR}$ genomic DNA purification kit (Qiagen Cat no. 158389) following the Whole-Blood-Enhanced Productivity protocol supplied by the manufacturer. The primers and PCR conditions are given in Table 1.

The specific VDR polymorphisms chosen were based on previous published literature as they are associated with functionality.

\section{Fokl PCR}

The reaction consisted of $12.5 \mu \mathrm{l}$ PCR master mix, 1.0 $\mu$ l Forward primer, $1.0 \mu$ l Reverse primer, $8.0 \mu \mathrm{l}$ water and $2.5 \mu$ l DNA. PCR machine conditions; denaturation $94^{\circ} \mathrm{C}$ for 5 minutes, then 40 cycles of denaturation $94^{\circ}$

Table 1 Primers for VDR polymorphisms

\begin{tabular}{lll}
\hline PCR & Forward primer & Reverse primer \\
\hline VDR & AGCTGGCCCTGGCACTGACTCTGCTCT & ATGGAAACACCTTGCTTCTTCTCCCTC \\
Fokl & GGGACGATGAGGGATGGACAGAGC & GGAAAGGGGTTAGGTTGGACAGGA \\
VDR & & GGAGAGGAGCCTCTGTCCCATTTG \\
Vaql & AACTTGCATGAGGAGGAGCATGTC & \\
\hline Bsml & & \\
\hline
\end{tabular}


$\mathrm{C}$ for 30 seconds, annealing $56^{\circ} \mathrm{C}$ 30seconds, extension $72^{\circ} \mathrm{C} 30$ seconds. The final extension was at $72^{\circ} \mathrm{C}$ for 5 minutes.

\section{Taq1a PCR}

The reaction consisted of $12.5 \mu \mathrm{l}$ PCR master mix, $1.0 \mu$ l Forward primer, 1.0 $\mu$ l Reverse primer, 8.0 $\mu \mathrm{l}$ water and $2.5 \mu$ l DNA. PCR machine conditions; denaturation $94^{\circ} \mathrm{C}$ for 5 minutes, then 40 cycles of denaturation $94^{\circ}$ $\mathrm{C}$ for 30 seconds, annealing $66^{\circ} \mathrm{C} 30$ seconds, extension $72^{\circ} \mathrm{C} 30$ seconds. The final extension was at $72^{\circ} \mathrm{C}$ for 5 minutes.

\section{Bsml PCR}

The reaction consisted of $12.5 \mu \mathrm{l}$ PCR master mix, $1.0 \mu \mathrm{l}$ Forward primer, $1.0 \mu \mathrm{l}$ Reverse primer, $8.0 \mu \mathrm{l}$ water and 2.5 $\mu$ l DNA. PCR machine conditions; denaturation $94^{\circ} \mathrm{C}$ for 5 minutes, then 30 cycles of denaturation $94^{\circ} \mathrm{C}$ for 30 seconds, annealing $56^{\circ} \mathrm{C}$ 30seconds, extension $72^{\circ} \mathrm{C}$ 30 seconds. The final extension was at $72^{\circ} \mathrm{C}$ for 5 minutes.

All PCR products were run on a $2 \%$ agarose gel with a PCR low ladder. The gel was run at $100 \mathrm{mV}$ for $15 \mathrm{~min}$ utes (Horizon 58, Biometra).

\section{VDR FokI RFLP}

To genotype the samples for the FokI polymorphism (rs2228570), a RFLP analysis was carried out by using the FokI restriction endonuclease enzyme (R0109S New England BioLabs). The reaction consisted of; $2 \mu$ l buffer,

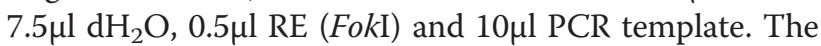
reaction digested at $37^{\circ} \mathrm{C}$ for 3 hours on PCR machine. The product was run on a $3 \%$ agarose gel. This resulted in the following bands; FF 265bp, Ff 265, 196 and 69bp, ff 196 and 69bp.

\section{VDR Taqla RFLP}

To genotype the samples for the TaqI $\underline{\alpha}$ polymorphism (rs731236), a RFLP analysis was carried out by using the TaqI $\underline{\alpha}$ restriction endonuclease enzyme (R0149T New England BioLabs). The reaction consisted of; $2 \mu$ l buffer,

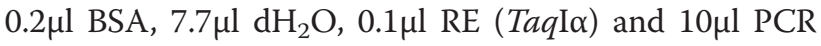
template. The reaction digested at $65^{\circ} \mathrm{C}$ for 3 hours on PCR machine. The product was run on a $3 \%$ agarose gel. This resulted in the following bands; TT 495bp, Tt 495, 290 and 205bp, tt 290 and 205bp.

\section{VDR BsmI RFLP}

To genotype the samples for the BsmI polymorphism (rs1544410), a RFLP analysis was carried out by using the $B s m I$ restriction endonuclease enzyme (R0134S New England BioLabs). The reaction consisted of; $2 \mu \mathrm{l}$ buffer, $7.75 \mu \mathrm{l} \mathrm{dH_{2 }} \mathrm{O}, 0.25 \mu \mathrm{l} \mathrm{RE}(B s m \mathrm{I})$ and $10 \mu \mathrm{l}$ PCR template. The reaction digested at $65^{\circ} \mathrm{C}$ for 3 hours on PCR machine. The product was run on a $3 \%$ agarose gel. This resulted in the following bands; $\mathrm{BB} 813 \mathrm{bp}, \mathrm{Bb} 813,670$ and $145 \mathrm{bp}$, bb 670 and 145bp.

\section{Statistical analysis}

Data were analysed using SPSS version 15 or STATA 8.2 (Stat Corporation, Texas, USA). The KolmogorovSmirnov test of normality was applied. Normally distributed data were expressed as mean and standard deviation (SD), skewed data as median and interquartile range (IQR). Spearman rank was used to assess nonparametric correlations. Wilcoxon and Mann Whitney U tests were used for paired and unpaired non-parametric tests respectively. Adjustment for seasonality and investigation of exacerbation and baseline 25-hydroxyvitamin $\mathrm{D}$ levels was done using year period sine and cosine terms. Results were therefore adjusted for repeated measures. The study was powered at 0.90 at a 2-sided 0.05 significance level to detect a difference in 25hydroxyvitamin D of 10nmol/L between frequent and infrequent exacerbators. This study was powered for the primary outcome.

\section{Results}

\section{Baseline patient characteristics}

Ninety seven COPD patients were studied, 61 male and 36 female. The patients had a mean $\mathrm{FEV}_{1}$ of $1.19 \mathrm{l}$ or $50.3 \%$ predicted. Ten COPD patients were on 25hydroxyvitamin D supplementation (Calcichew D3), and were not included in the following analysis unless otherwise stated. Each tablet of calcichew D3 contains 10 micrograms of colecalciferol and patients usually take 2 a day. The baseline characteristics are reported in Table 2.

Table 2 Baseline Characteristics of 97 patients

\begin{tabular}{ll}
\hline & COPD patients ( $\mathbf{n}=97)$ Mean (SD) \\
\hline Age (years) & $71.8(8.8)$ \\
FEV1 (litre) & $1.19(0.54)$ \\
FEV1 (\% predicted) & $50.3(19.7)$ \\
FVC (litre) & $2.5(0.84)$ \\
BMl (kgm ${ }^{-2}$ ) & $27.0(6.0)$ \\
Pack years smoking & $50.7(34.2)$ \\
SpO 2 (\%) on air & $95(2)$ \\
25-hydroxyvitamin D nmol/L & Median (IQR) \\
Summer & $41.3(26.8-64.8)$ \\
Winter & $27.8(19.4-44.4)$ \\
& Number (\%) \\
Male & $61(62.9)$ \\
Frequent exacerbators & $28(28.9)$ \\
Current smokers & $25(25.8)$ \\
\hline
\end{tabular}




\section{Seasonal variation and 25-hydroxyvitamin D levels in COPD}

COPD patients had lower 25-hydroxyvitamin D levels in winter compared to summer; medians $26.7 \mathrm{nmol} / \mathrm{L}$ (IQR $17.8-41.2)$ and $39.6 \mathrm{nmol} / \mathrm{L}(26.4-62.9)$; $\mathrm{p}<0.001$. Within individuals, summer and winter 25-hydroxyvitamin D levels varied by $10 \%$ monthly and by $50 \%$ between summer and winter, with summer levels being higher. Patients taking Calcichew D3 did not show the same significant seasonal variation in 25-hydroxyvitamin D levels; winter median $58.1 \mathrm{nmol} / \mathrm{L}$ (35.2 - 69.6), summer median $56.2 \mathrm{nmol} / \mathrm{L}(33.9$ - 73.1; p $>0.05$. The seasonal difference in 25-hydroxyvitamin D levels between these patients is illustrated in Figure 1. There were no differences in summer 25-hydroxyvitamin D levels between current smokers and ex-smokers, medians; $45.5 \mathrm{nmol} / \mathrm{L}$ $(27.4-63.3)$ and $40.3 \mathrm{nmol} / \mathrm{L}(26.7-66.3)$ or winter 25 hydroxyvitamin D levels; medians $27.0 \mathrm{nmol} / \mathrm{L}$ (14.6 47.7) and $28.0 \mathrm{nmol} / \mathrm{L}(19.9$ - 43.7).

\section{5-hydroxyvitamin D levels in frequent and infrequent exacerbators}

Figure 2 shows that there was no difference in 25hydroxyvitamin D levels between frequent exacerbators (1/3 of the cohort) and infrequent exacerbators in the summer; medians 44.1nmol/L (29.1 - 68.0) and $39.4 \mathrm{nmol} / \mathrm{L}(22.3$ - 59.2) or winter; medians $24.9 \mathrm{nmol} / \mathrm{L}$ $(14.3$ - 43.1) and $27.1 \mathrm{nmol} / \mathrm{L}(19.9$ - 37.6). The proportion of patients' deficient, insufficient and sufficient in 25-hydroxyvitamin D was the same in both frequent and infrequent exacerbators groups. Exacerbation history was available in a subset of 10 patients before and after treatment with Calcichew D3. There was no difference in actual exacerbation number from year 1 to $2 ; \mathrm{p}=0.45$, or in exacerbation frequency from year 1 to $2 ; \mathrm{p}=0.38$.

\section{Time outdoors and 25-hydroxyvitamin D levels}

Figure 3 shows that shorter day length on the day of sampling was associated with lower levels of 25hydroxyvitamin D (coef 1.65 , se $0.69 ; \mathrm{p}=0.02$ ). Patients who spent less time outdoors in the 14 days prior to sampling also had lower 25-hydroxyvitamin D levels coef 2.36, se0.96; $\mathrm{p}=0.02$ ). This was independent of day length.

\section{5-hydroxyvitamin D levels and exacerbations of COPD}

We measured serum 25-hydroxyvitamin D levels in 58 exacerbations; 1 per patient in the study period. Adjusting for seasonality, there was no difference in 25-hydroxyvitamin D levels between baseline and exacerbation; medians $36.2 \mathrm{nmol} / \mathrm{L}$ (IQR 22.4-59.4) and 33.3nmol/L (23.0-49.7); $\mathrm{p}=0.43$.

\section{5-hydroxyvitamin D and HRV exacerbations}

46 exacerbations were tested for the presence of HRV in sputum or NPS. HRV positive exacerbations $(n=12$, viral load $>175 \mathrm{pfu} / \mathrm{ml}$; [28] were not associated with lower 25-hydroxyvitamin D levels at exacerbation than exacerbations that did not test positive for HRV; medians 30.0nmol/L (20.4 - 57.8) and 30.6nmol/L (19.4 - 48.7). HRV load in sputum or NPS at exacerbation did not

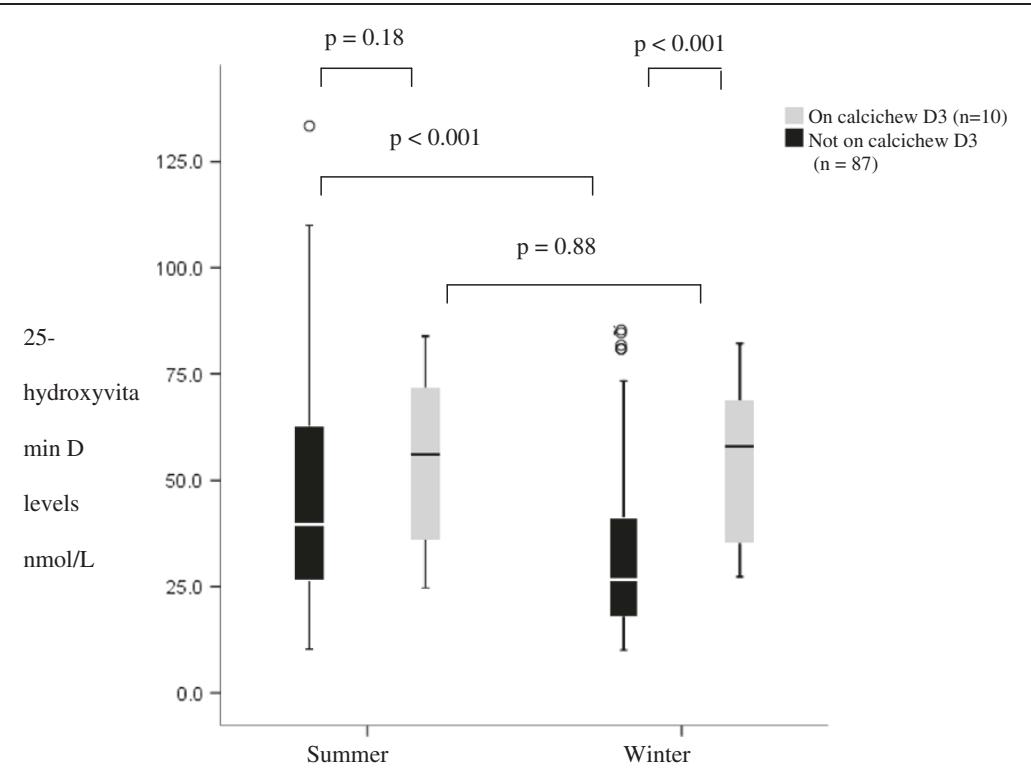

Figure 1 25-hydroxyvitamin D levels in COPD patients in summer and winter in those on and not on calcium and 25-hydroxyvitamin D supplementation. Data are presented as median, with the boxes representing the interquartile range and the whiskers representing SD. O: extreme outliers. 


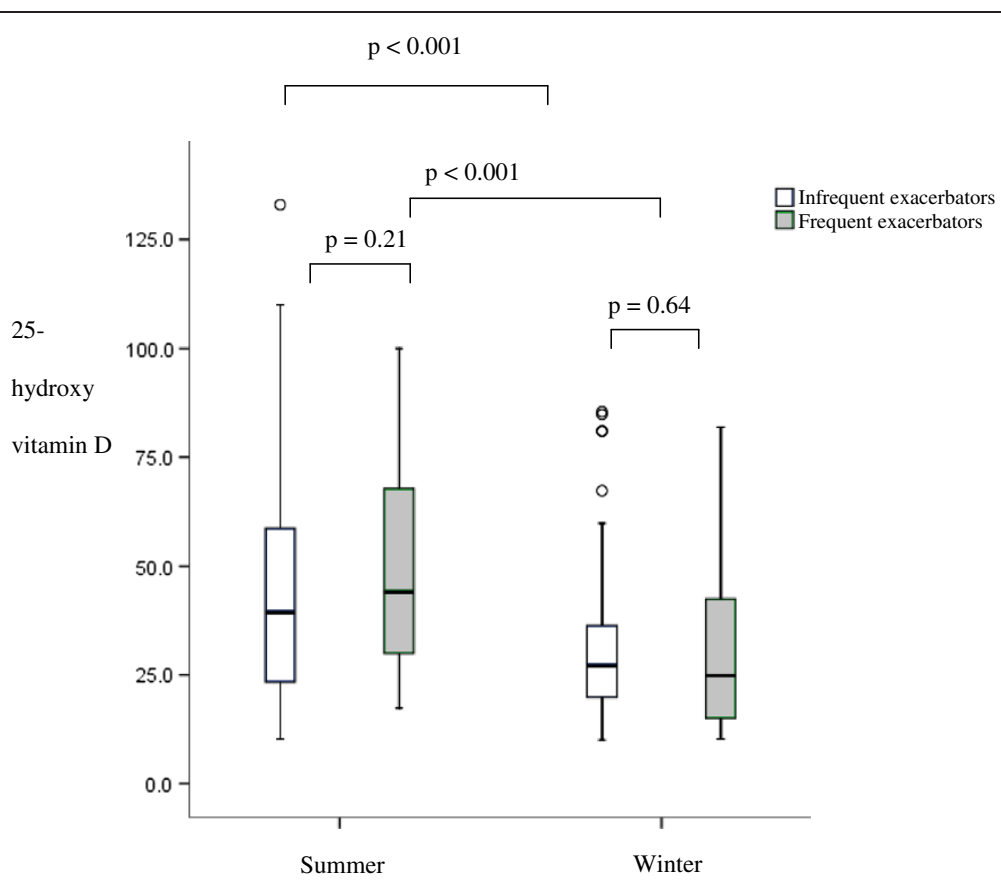

Figure 2 25-hydroxyvitamin D levels in summer and winter in frequent and infrequent exacerbators. Data are presented as median, with the boxes representing the interquartile range and the whiskers representing SD. O: extreme outliers.

correlate with exacerbation 25-hydroxyvitamin D levels (data not shown). When including all exacerbations per patient taken over the study period tested for HRV, patients deficient in 25-hydroxyvitamin $\mathrm{D}$ at baseline did not have an increased proportion of HRV positive exacerbations compared to those insufficient or sufficient. This is illustrated in Table 3. The presence of cold symptoms at exacerbation was not related to vitamin D deficiency $(\mathrm{p}>0.05)$.

\section{Exacerbation length and severity}

There was no relationship with 25-hydroxyvitamin D levels either at that exacerbation or the baseline preceding that exacerbation and the length of the exacerbation;
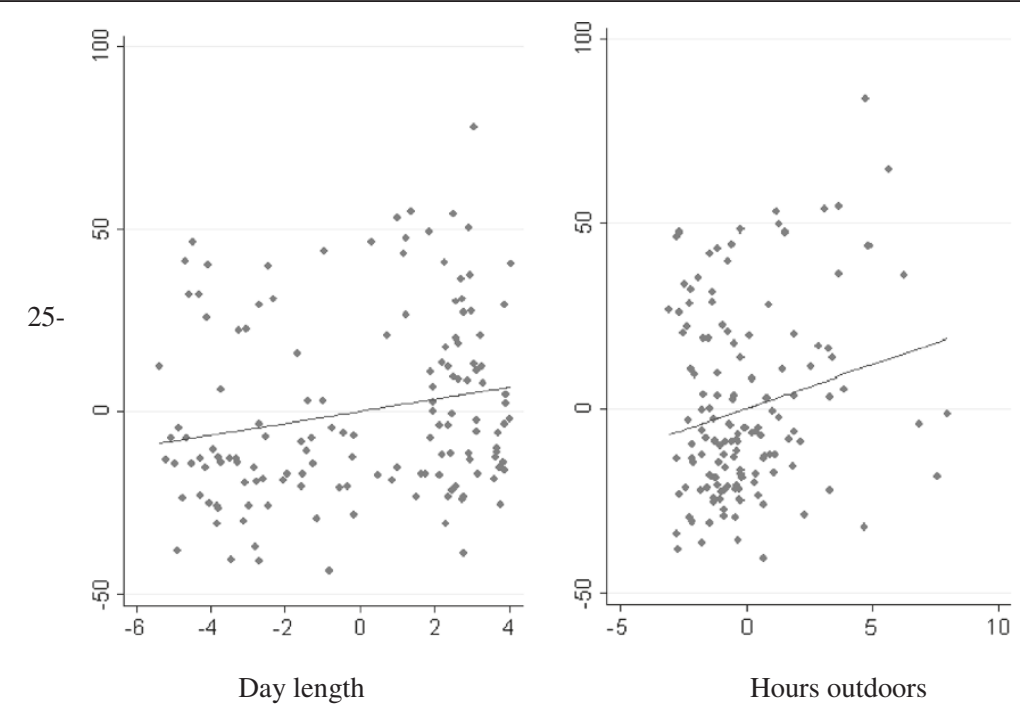

Figure 3 Adjusted partial residual plot of the relationship between 25-hydroxyvitamin D levels and (1) day length (hours), and (2) hours outdoors. The graphs show the effect of each variable on 25 -hydroxyvitamin D independently of the other variable. The zero value is the annual average. 
Table 3 25-hydroxyvitamin D status and positivity for $\mathrm{HRV}$ at exacerbation

\begin{tabular}{|c|c|c|c|}
\hline 25-hydroxyvitamin & positive fo & exacerbation & Total \\
\hline D status & No & Yes & \\
\hline Deficient & $4(25.0 \%)$ & 7 (23.3\%) & 11 \\
\hline Insufficient & $10(62.5 \%)$ & 19 (63.3\%) & 29 \\
\hline Sufficient & $2(12.5 \%)$ & $4(13.3 \%)$ & 6 \\
\hline Total & 16 & 30 & 46 \\
\hline
\end{tabular}

25-hydroxyvitamin $D$ deficiency was defined as $<25 \mathrm{nmol} / \mathrm{L}$, insufficiency $25-75 \mathrm{nmol} / \mathrm{L}$ and sufficiency $>75 \mathrm{nmol} / \mathrm{L}$ (conversion factor of 2.5 for $\mathrm{nmol} / \mathrm{L}$ from $\mathrm{ng} / \mathrm{ml}$ ).

rho $=-0.41: \mathrm{p}=0.12$ and rho $=-0.41: \mathrm{p}=0.12$ respectively or time to the next exacerbation; rho $=-0.11$, $\mathrm{p}=0.66$ and rho $=-0.06, \mathrm{p}=0.81$ respectively. All exacerbations recovered.

\section{VDR polymorphisms}

All genotypes were within Hardy Weinberg equilibrium. The FokI polymorphism was not related to TaqI or $B s m I$, however the BsmI and TaqI polymorphisms were linked ( $\mathrm{p}<0.001)$. There was no relationship with genotyping and exacerbation frequency for any of the polymorphisms as illustrated in Table 4.

\section{Discussion}

We have investigated several aspects of 25hydroxyvitamin D deficiency in a well characterised cohort of COPD patients and shown that independent of day length, COPD patients who spend less time outdoors have lower 25-hydroxyvitamin D levels. In this study we found that patients on Calcichew D3 had much higher levels of 25-hydroxyvitamin D than COPD patients not on 25-hydroxyvitamin D supplementation and showed much less seasonal variation in 25hydroxyvitamin D levels. This is an interesting finding as several studies have investigated the pharmacokinetics of 25-hydroxyvitamin $\mathrm{D}$, and it is thought that the amount of cholecalciferol in Calcichew is far below the amount required to treat deficiency and maintain a stable 25hydroxyvitamin $\mathrm{D}$ level. This suggests that perhaps these patients may differ with respect to underlying subphenotype or co-morbidities (e.g. osteoporosis). However with only 10 patients in this group it is not possible to reach firm conclusions.

\section{Outdoor activity and 25-hydroxyvitamin D levels}

From this study it appears that 25-hydroxyvitamin D levels are driven primarily by season and outdoor activity, with patients with lower 25-hydroxyvitamin D levels spending less time outdoors in the 14 days preceding sampling. This has implications for pulmonary rehabilitation, patient education and lifestyle modification. Independent of 25-hydroxyvitamin D status, reduced activity in COPD is related to poorer prognosis [31]. Perhaps outdoor pulmonary rehabilitation should be encouraged in those COPD patients deficient in 25-hydroxyvitamin D.

A large proportion of the elderly population in the USA and Europe are 25-hydroxyvitamin D deficient [32] and those with COPD are at particularly high risk [1]. Studies in asthma linking low 25-hydroxyvitamin D levels with disease severity have postulated the relationship may be secondary to time spent indoors [33]. This is also likely to be important in COPD [14]. 25hydroxyvitamin $\mathrm{D}$ deficiency in the COPD population may reflect poor general health status rather than having particular importance in the natural progression of COPD. However, if it were that simple, patients with COPD living in tropical countries should have milder disease and fewer exacerbations.

\section{5-hydroxyvitamin D levels and exacerbations and exacerbation frequency}

Patients deficient in 25-hydroxyvitamin $\mathrm{D}$ in the stable state $(<25 \mathrm{nmol} / \mathrm{L})$, were not more likely to be frequent exacerbators and did not have a shorter time to their next exacerbation than those insufficient or sufficient in 25-hydroxyvitamin D. 25-hydroxyvitamin D levels were unchanged between baseline and exacerbation in COPD when adjustments were made for seasonality and we did not find a relationship between 25 -hydroxyvitamin D deficiency and exacerbation severity. This is in keeping with a recent study which found that low baseline 25hydroxyvitamin D levels in patients with severe COPD did not predict subsequent exacerbations [34]. A recent RCT has also shown that high dose vitamin D

\begin{tabular}{lllll}
\multicolumn{5}{l}{ Table 4 VDR polymorphisms and exacerbation frequency } \\
\hline SNP & Genotype & $\begin{array}{l}\text { Frequent } \\
\text { exacerbators } \\
\text { (n= 28) }\end{array}$ & $\begin{array}{l}\text { Infrequent } \\
\text { exacerbators } \\
\text { ( } \mathbf{n}=68)\end{array}$ & $\begin{array}{l}\text { Chi squared } \\
\text { P value }\end{array}$ \\
\hline Rs1544410 & $\mathrm{BB}$ & $3(10.7 \%)$ & $15(22.1 \%)$ & \\
Bsml & $\mathrm{Bb}$ & $12(42.9 \%)$ & $26(38.2 \%)$ & 0.43 \\
& $\mathrm{Bb}$ & $13(46.4 \%)$ & $27(39.7 \%)$ & \\
HWE p value & & 0.93 & 0.08 & \\
& & $(\mathrm{n}=26)$ & $(\mathrm{n}=66)$ & \\
Rs731236 & $\mathrm{TT}$ & $10(38.5 \%)$ & $24(36.4 \%)$ & \\
Taql & $\mathrm{Tt}$ & $13(50 \%)$ & $29(43.9 \%)$ & 0.64 \\
& $\mathrm{Tt}$ & $3(11.5 \%)$ & $13(19.7 \%)$ & \\
HWE p value & & 0.69 & 0.43 \\
& & $(\mathrm{n}=28)$ & $(\mathrm{n}=68)$ & \\
Rs2228570 & $\mathrm{FF}$ & $10(35.7 \%)$ & $21(30.9 \%)$ & \\
Fokl & $\mathrm{Ff}$ & $14(50.0 \%)$ & $38(55.9 \%)$ & 0.87 \\
& $\mathrm{Ff}$ & $4(14.3 \%)$ & $9(13.2 \%)$ & \\
HWE p value & & 0.80 & 0.21 & \\
\hline & & & & \\
\hline
\end{tabular}


supplementation in COPD patients did not reduce exacerbation incidence [35]. However the authors of this study in a post-hoc analysis suggested that in patients with the most severe vitamin D deficiency at baseline, supplementation may reduce future exacerbations.

Influenza and other viruses show a distinct predilection for wintertime infectivity, and exacerbations of COPD are significantly more likely to occur in the winter. 25-hydroxyvitamin D deficiency has been associated with self-reported upper respiratory tract infections (URTI) [36,37]. As HRV is the commonest cause of colds and present in over $50 \%$ of COPD exacerbations, we chose specifically to investigate a relationship between HRV exacerbations and 25-hydroxyvitamin D deficiency. We did not find a relationship between 25hydroxyvitamin D deficiency and the presence of HRV at exacerbation or HRV load at exacerbation. In other diseases, 25-hydroxyvitamin D supplementation studies have shown mixed results with regards to preventing viral and bacterial infections $[38,39]$. We did not have bacterial culture data available in this study and were unable to investigate any association between vitamin $\mathrm{D}$ levels and bacterial exacerbations.

\section{VDR polymorphisms}

We did not find a relationship between VDR polymorphisms and exacerbation frequency. However, the FokI, and TaqI Vitamin D receptor polymorphisms have been shown to be associated with lower respiratory tract infections in children [40]. Genetic variants in the 25hydroxyvitamin $\mathrm{D}$ pathway have been associated with COPD $[1,24]$. Although GWAS studies did not find VDR to be an important risk gene for COPD, associations of VDR with risk for infections [40] has been found in investigating interactions between low 25-hydroxyvitamin D levels and the VDR. Many polymorphisms exist in the VDR gene and the influence of these polymorphisms on VDR protein function may influence immunomodulatory responses [27]. To date no study has found a link with VDR polymorphisms and airway infection in COPD although there are several mechanisms by which activated 25-hydroxyvitamin D binding to the VDR could modulate viral lower respiratory tract disease [41-43]. Our study was powered on the primary outcome and our sample size for a genetic study is relatively small. This may explain our negative findings.

There are several strengths to this study. The London COPD cohort is a well characterised cohort of COPD patients with detailed information on exacerbations and exacerbation frequency. In this cohort monitoring visits are predefined at regular time intervals and driven by clinical visits because of exacerbations thus allowing information to be obtained on 25-hydroxyvitamin D at baseline and exacerbation.
We do not actually know what constitutes 25hydroxyvitamin D deficiency, particularly in the context of its immunomodulatory properties. In terms of calcaemic effects, levels below $50 \mathrm{nmol} / \mathrm{L}$ are probably deficient $[3,44]$. With regards to the immunomodulatory mechanisms of 25-hydroxyvitamin D it has even been suggested that levels $>100 \mathrm{nmol} / \mathrm{L}$ are needed for optimal immune functioning. There is much to be learned about the role of 25-hydroxyvitamin $\mathrm{D}$ in COPD and the mechanisms by which increasing 25-hydroxyvitamin D levels into the normal range would influence the natural history of COPD.

\section{Conclusions}

In conclusion, we have shown that independent of day length, patients who spend less time outdoors have lower 25-hydroxyvitamin D levels. Low 25-hydroxyvitamin D levels in COPD are not associated with exacerbation frequency and do increase susceptibility to HRV exacerbations.

\section{Competing interests}

The authors declare that they have no competing interests.

\section{Acknowledgements}

This research was funded by a grant from the National Institute of Health USA; RO1 HL082578. We thank the Department of Clinical Biochemistry, Royal Free Hospital NHS Trust for analyzing 25-hydroxyvitamin D samples. We also thank Dr James Goldring for help in recruiting COPD patients and with sampling.

\section{Author details}

${ }^{1}$ Academic Unit of Respiratory Medicine, University College London Medical School, Royal Free Campus, Rowland Hill Street, London, UK. ${ }^{2}$ Department of Clinical Biochemistry, Royal Free Hospital, Pond Street, London, UK.

\section{Authors' contributions}

$J K Q, G C D, J R H, N W, M T$ and JAW contributed to the conception and design of the study. JKQ, to the acquisition of samples, NW to vitamin D processing, JKQ and GCD to data analysis, JKQ, GCD, JRH, NW, MT and JAW to interpretation of data. JKQ wrote the first draft of the manuscript and all authors contributed to subsequent drafts. All authors read and approved the final manuscript.

Received: 13 January 2012 Accepted: 22 June 2012

Published: 22 June 2012

\section{References}

1. Janssens W, Lehouck A, Carremans C, Bouillon R, Mathieu C, Decramer M: 25-hydroxyvitamin $D$ beyond bones in chronic obstructive pulmonary disease: time to act. Am J Respir Crit Care Med 2009, 179(8):630-636.

2. Mora JR, Iwata $M$, von Andrian UH: Vitmain effects on the immune system: vitamins A and D take centre stage. Nature Reviews Immunol 2008, 8:685-698.

3. Holik MF: 25-hydroxyvitamin D deficiency. N Eng J Med 2007, 357:266-281.

4. Waterhouse JC, Perez TH, Albert PJ: Reversing bacteria-induced 25-hydroxyvitamin $D$ receptor dysfunction is key to autoimmune disease. Ann N Y Acad Sci 2009, 1173:757-765.

5. Global Initiative for Chronic Obstructive Lung Disease: Global Strategy for the diagnosis, management and prevention of chronic obstructive pulmonary disease. (GOLD). 2006. http://www.goldcopd.org. Accessed 17 th May 2009.

6. Seemungal TA, Donaldson GC, Paul EA, Bestall JC, Jeffries DJ, Wedzicha JA: Effect of exacerbation on quality of life in patients with chronic obstructive pulmonary disease. Am J Respir Crit Care Med 1998, 157:1418-1422.

7. Spencer $S$, Jones PW: Time course of recovery of health status following an infective exacerbation of chronic bronchitis. Thorax 2003, 58:589-593. 
8. Donaldson GC, Seemungal TAR, Bhowmik A, Wedzicha JA: Relationship between exacerbation frequency and lung function decline in chronic obstructive pulmonary disease. Thorax 2002, 57:847-852.

9. O'Brien JA, Ward AJ, Jones MKC, McMillan C, Lordan N: Utilization of health care services by patients with chronic obstructive pulmonary disease. Respir Med 2003, 97(1):S53-S58.

10. Groenewegen KH, Schols AMWJ, Wouters EFM: Mortality and mortality related factors after hospitalisation for acute exacerbation of COPD. Chest 2003, 124:459-467.

11. Seemungal TAR, Harper-Owen R, Bhowmik A, et al: Respiratory viruses, symptoms and inflammatory markers in acute exacerbations and stable chronic obstructive pulmonary disease. Am J Respir Crit Care Med 2001 164:1618-1623.

12. Wilkinson TMA, Hurst JR, Perera WR, et al: Effect of interactions between lower airway bacterial and rhinoviral infection in exacerbations of COPD. Chest 2006, 129:317-324.

13. Hurst JR, Vestbo J, Anzueto A, Locantore N, Müllerova $H$, Tal-Singer $R$, Miller B, Lomas DA, Agusti A, Macnee W, Calverley P, Rennard S, Wouters EF, Wedzicha JA: Evaluation of COPD Longitudinally to Identify Predictive Surrogate Endpoints (ECLIPSE) Investigators. Susceptibility to exacerbation in chronic obstructive pulmonary disease. $N$ Engl J Med 2010, 363(12):1128-1138.

14. Donaldson GC, Wilkinson TM, Hurst JR, Perera WR, Wedzicha JA: Exacerbations and time spent outdoors in chronic obstructive pulmonary disease. Am J Respir Crit Care Med 2005, 171:446-452.

15. Kanner RE, Anthonisen NR, Connett JE: Lower respiratory illnesses promote FEV1 decline in current smokers but not ex-smokers with mild chronic obstructive pulmonary disease. Am J Respir Crit Care Med 2001 164:358-364.

16. Celli BR, Thomas NE, Anderson JA, Ferguson GT, Jenkins CR, Jones PW, Vestbo J, Knobil K, Yates JC, Calverley PMA: Effect of Pharmacotherapy on Rate of Decline of Lung Function in Chronic Obstructive Pulmonary Disease: Results from the TORCH Study. Am J Respir Crit Care Med 2008, 178:332-338.

17. Bhowmik A, Seemungal TAR, Sapsford RJ, Wedzicha JA: Relation of sputum inflammatory markers to symptoms and lung function changes in COPD exacerbations. Thorax 2000, 55:114-120.

18. Soler-Cataluna JJ, Martinez-Garcia MA, Roman Sanchez P, Salcedo E, Navarro M, Ochando R: Severe acute exacerbations and mortality in patients with chronic obstructive pulmonary disease. Thorax 2005, 57:137-141.

19. Eccles R: An Explanation for the Seasonality of Acute Upper Respiratory Tract Viral Infections. Acta Otolaryngol 2002, 122(2):183-191.

20. Hope-Simpson RE: The role of season in the epidemiology of influenza. J Hyg (Lond) 1981, 86(1):35-47.

21. Leow L, Simpson T, Cursons R, Karalus N, Hancox RJ: Vitamin D, innate immunity and outcomes in community acquired pneumonia. Respirology 2011, 16(4):611-616.

22. Janssens W, Bouillon R, Claes B, Carremans C, Lehouck A, Buysschaert I, Coolen J, Mathieu C, Decramer M, Lambrechts D: 25-hydroxyvitamin D deficiency is highly prevalent in COPD and correlates with variants in the 25-hydroxyvitamin D-binding gene. Thorax 2010, 65(3):215-220.

23. Forli L, Bjortuft $\mathrm{O}$, Boe J: Vitamin D status in relation to nutritional depletion and muscle function in patients with advanced pulmonary disease. Exp Lung Res 2009 Aug, 35(6):524-538.

24. Schellenberg D, Pare PD, Weir TD, Spinelli JJ, Walker BAM, Sandford AJ: 25-hydroxyvitamin D Binding Protein Variants and the Risk of COPD. Am J Respir Crit Care Med 1998, 157:957-961.

25. Lauridsen $A L$, Vestergaard $P$, et al: Plasma concentrations of 25-Hydroxy-25-hydroxyvitamin D and 1,25-Dihydroxy-25-hydroxyvitamin D are Related to the Phenotype of Gc (25-hydroxyvitamin D-Binding Protein): A Cross-sectional Study on 595 Early Postmenopausal Women. Calcified Tissue International, Springer New York 2005, 77(1):15-22.

26. Taes YEC, Goemaere S, Huang G, Van Pottelbergh I, De Bacquer D, Verhasselt B, Van den Broeke C, Delanghe JR, Kaufman JM: 25-hydroxyvitamin $D$ binding protein, bone status and body composition in community-dwelling elderly men. Bone 2006, 38(5):701-707.
27. Uitterlinden AG, Fang Y, Van Meurs JB, Pols HA, Van Leeuwen JP: Genetics and biology of 25-hydroxyvitamin D receptor polymorphisms. Gene 2004, 338(2):143-156.

28. Quint JK, Donaldson GC, Goldring JJ, Baghai-Ravary R, Hurst JR, Wedzicha JA: Serum IP-10 as a biomarker of human rhinovirus infection at exacerbation of COPD. Chest 2010 Apr, 137(4):812-822.

29. Garcia-Aymerich J, Lange P, Benet M, Schnohr P, Antó JM: Regular physical activity reduces hospital admission and mortality in chronic obstructive pulmonary disease: a population based cohort study. Thorax 2006, 61(9):772-778.

30. Chapuy MC, Preziosi P, Maamer M, Arnaud S, Galan P, Hercberg S, Meunier PJ: Prevalence of 25-hydroxyvitamin D insufficiency in an adult normal population. Osteoporos Int 1997, 7(5):439-443.

31. Brehm JM, Celedón JC, Soto-Quiros ME, Avila L, Hunninghake GM, Forno E, Laskey D, Sylvia JS, Hollis BW, Weiss ST, Litonjua AA: Serum 25-hydroxyvitamin D levels and markers of severity of childhood asthma in Costa Rica. Am J Respir Crit Care Med 2009, 179(9):765-771.

32. Kunisaki KM, Niewoehner DE, Connett JE: COPD Clinical Research Network, Vitamin D levels and risk of acute exacerbations of chronic obstructive pulmonary disease: a prospective cohort study. Am J Respir Crit Care Med 2012 Feb 1, 185(3):286-290.

33. Lehouck A, Mathieu C, Carremans C, Baeke F, Verhaegen J, Van Eldere J, Decallonne B, Bouillon R, Decramer M, Janssens W: High doses of vitamin $D$ to reduce exacerbations in chronic obstructive pulmonary disease: a randomized trial. Ann Intern Med 2012 Jan 17, 156(2):105-114.

34. Ginde AA, Mansbach JM, Camargo CA Jr: Association between serum 25-hydroxy25-hydroxyvitamin D level and upper respiratory tract infection in the Third National Health and Nutrition Examination Survey. Arch Intern Med 2009, 169(4):384-390.

35. Laaksi I, Ruohola JP, Tuohimaa P, Auvinen A, Haataja R, Pihlajamäki H, Ylikomi T: An association of serum 25-hydroxyvitamin D concentrations $<40 \mathrm{nmol} / \mathrm{L}$ with acute respiratory tract infection in young Finnish men. Am J Clin Nutr 2007, 86(3):714-717.

36. Martineau AR, Wilkinson RJ, Wilkinson KA, Newton SM, Kampmann B, Hall BM, Packe GE, Davidson RN, Eldridge SM, Maunsell ZJ, Rainbow SJ, Berry JL, Griffiths CJ: A Single Dose of 25-hydroxyvitamin D Enhances Immunity to Mycobacteria Am. J. Respir. Crit. Care Med 2007, 176:208-213.

37. Wejse C, Gomes VF, Rabna P, Gustafson P, Aaby P, Lisse IM, Andersen PL, Glerup H, Sodemann M: 25-hydroxyvitamin D as Supplementary Treatment for Tuberculosis: A Double-blind, Randomized, Placebo-controlled Trial. Am J Respir Crit Care Med 2009, 179:843-850.

38. Roth $D E$, Jones $A B$, Prosser $C$, Robinson JL, Vohra S: 25-hydroxyvitamin D receptor polymorphisms and the risk of acute lower respiratory tract infection in early childhood. J Infect Dis 2008, 197(5):676-680.

39. Sadeghi K, Wessner B, Laggner U, et al: 25-hydroxyvitamin D3 down-regulates monocyte TLR expression and triggers hyporesponsiveness to pathogen associated molecular patterns. Eur $J$ Immunol 2006, 36:361-370.

40. Bhalla AK, Amento EP, Krane SM: Differential effects of 1,25 dihydroxy25-hydroxyvitamin D3 on human lymphocytes and monocyte/macrophages: inhibition of interleukin 2 and augmentation of interleukin1 production. Cell Immunol 1986, 98:311-322.

41. Liu PT, Stenger S, Li H, et al: Toll-like receptor triggering of a 25-hydroxyvitamin D-mediated human antimicrobial response. Science 2006, 311:1770-1773.

42. Norman AW, Bouillon R, Whiting SJ, Vieth R, Lips P: 13th Workshop consensus for 25-hydroxyvitamin $D$ nutritional guidelines The Journal of Steroid Biochemistry and. Mol Biol 2007, 103(3-5):204-205.

43. Quint JK, Donaldson GC, Hurst JR, Goldring JJ, Seemungal TR, Wedzicha JA: Predictive accuracy of patient reported exacerbation frequency in chronic obstructive pulmonary disease. Eur Respir J 2011, 37(3):501-507.

44. Bhowmik A, Seemungal TAR, Sapsford RJ, Devalia JL, Wedzicha JA: Comparison of spontaneous and induced sputum for investigation of airway inflammation in chronic obstructive pulmonary disease. Thorax 1998, 53:953-956.

doi:10.1186/1471-2466-12-28

Cite this article as: Quint et al:: 25-hydroxyvitamin D deficiency, exacerbation frequency and human rhinovirus exacerbations in chronic obstructive pulmonary disease. BMC Pulmonary Medicine 2012 12:28. 